\title{
Investor sentiment and the mean-variance relationship: European evidence
}

\begin{abstract}
This paper investigates the impact of investor sentiment on the mean-variance relationship in 14 European stock markets. Applying three approaches to define investors' neutrality and determine high and low sentiment periods, we find that individual investors' increased presence and trading over high-sentiment periods would undermine the risk-return tradeoff. More importantly, we report that investors' optimism (pessimism) is more determined by their normal sentiment state, represented by the all-period average sentiment level, rather than the neutrality value set in sentiment surveys.
\end{abstract}

Keywords: Investor sentiment; Mean-variance relationship; Risk-return tradeoff; Volatility

JEL classification: G12; G14; G15; G41

\section{Highlights}

- We test the impact of investor sentiment on the mean-variance relationship.

- Empirical analyses are based on 14 European stock markets.

- Three approaches are adopted to determine high and low sentiment periods.

- Results show high sentiment periods would see the undermined risk-return tradeoff.

- Investors' optimism (pessimism) is more determined by their normal sentiment state. 


\section{Introduction}

The mean-variance relationship has long been a focus in literature. While rational asset pricing models theorize a positive mean-variance relationship (Merton, 1973), i.e. the risk-return tradeoff, empirical studies report, at best, mixed evidence (French et al., 1987; Harvey, 2001; Pástor et al., 2008). Behavioral theories emphasize the importance of investor sentiment in explaining stock prices, volatility, and returns (De Long et al., 1990; Baker and Wurgler, 2006; Schmeling, 2009). Although two streams of thoughts come from different camps-traditional and behavioral, combining two together, Yu and Yuan (2011) find that stock market expected returns are positively related to market conditional variance over low-sentiment periods but unrelated to conditional variance over high-sentiment periods.

Extending the earlier evidence, this paper aims at providing further insights into the impact of investor sentiment on the mean-variance relationship, which is developed on two arguments. First, individual investors exert greater impact on stock markets over high- than low-sentiment periods because of their unwillingness to take short positions (Barber and Odean, 2008; Antoniou et al., 2016). Second, unsophisticated individual investors would misestimate the risk and distort the mean-variance relationship (Yu and Yuan, 2011). These two arguments together indicate that individual investors' increased trading over high-sentiment periods would distort the risk-return tradeoff.

In particular, we base our empirical analyses in 14 European stock markets. This enlarged dataset brings the following merits. First, we provide out-of-sample evidence for the impact of investor sentiment on the mean-variance relationship outside the US, which appears necessary in examining market anomalies (Griffin et al., 2003; Ang et al., 2009; Schmeling, 2009). Second, statistically, the panel dataset including more than one stock market can enhance the test power (Ang and Bekaert, 2007). Third, the presented mean-variance relationship would be instructive to investors regarding investment management within and across markets. Fourth, we hypothesize 
that individual investors' optimism and pessimism is not fully reflected by sentiment surveys, but more importantly, depends on their real feelings relative to their normal sentiment state. Taking the regional perspective facilitates to examine this new hypothesis and provide abundant evidence based on the panel dataset and wider scopes of individual markets.

In this study, conditional volatility is measured via four models including the rolling window (RW), GARCH, GJR-GARCH, and EGARCH models in that the mean-variance relationship is subject to the choice of volatility models (Ghysels et al., 2005). We start with checking the meanvariance relationship in panel dataset by pooling all 14 markets together. Results from the entire sample reveal the significantly negative mean-variance relationship, inconsistent with rational asset pricing theories (Merton, 1980). To explore the role of investor sentiment in influencing the mean-variance relationship, we split the entire sample into two subsamples-high-sentiment periods (HSPs) and low-sentiment periods (LSPs), according to whether the sentiment level is above or below the neutrality value (NV) set by sentiment surveys (Yu and Yuan, 2011; Antoniou et al., 2016). We report a mixed and normally insignificant relationship over LSPs, but a significantly negative relationship over HSPs, which suggests that individual investors' increased presence and trading over HSPs would undermine the risk-return tradeoff. A further investigation into the relationship between stock returns and contemporaneous volatility innovations indirectly supports our results. The same procedure is replicated on each individual market, and results show that despite the heterogeneity, the presented impact of investor sentiment on the mean-variance relationship obtains supports in over the half individual markets.

Further, we argue that the NV in sentiment surveys does not completely determine investors' optimism or pessimism due to investors' natural proneness to optimism or pessimism in one specific market. In one market where investors are apt to be optimistic (pessimistic), a disclosed sentiment level that is marginally above (below) the neutrality value of sentiment surveys may signify investors' bearishness (bullishness) rather than bullishness (bearishness). To confirm this, 
we propose two new approaches to determine HSPs and LSPs - whether the sentiment level is above or below (i) the all-period average level of sentiment and (ii) the past three-year historical average level of sentiment. The first approach depicts the normal sentiment state as it takes allperiod sentiment levels into account. The second approach is a weak form of the first one as it considers the past three years. Panel results from two new approaches are consistent with the previous that HSPs observe the weakened risk-return tradeoff. Notably, the separation criterion based on the all-period average presents strong findings that stock returns and conditional volatility are positively related over LSPs but negatively related over HSPs. This evidence indicates that investors' trading and the impact of investor sentiment on the mean-variance relationship would depend more on their normal sentiment level. Specifically, individual investors' pessimism makes them reluctant to trade over LSPs and with a higher proportion of sophisticated investors, the market sees a risk-return tradeoff as rational asset pricing theories argue. However, investors' optimism brings about their increased participation in stock trading over HSPs, which distorts the risk-return tradeoff and leads to the negative mean-variance relationship. Evidence on individual markets largely support that on panel dataset.

The rest of the paper proceeds as follows. Section 2 reviews extant studies on the mean-variance relationship and investor sentiment. Section 3 illustrates the data and descriptive statistics. Section 4 details the methodology in measuring conditional volatility and assessing the mean-variance relationship. Section 5 provides empirical results and discussions, and Section 6 concludes.

\section{Earlier literature}

Standard financial theories point out a positive relationship between stock returns and conditional volatility, i.e., the risk-return tradeoff, which is regarded as the 'first fundamental law of finance' (Ghysels et al., 2005, p. 510). For instance, Merton (1973) proposes the intertemporal capital asset pricing model and argues that conditional expected market returns and conditional variance are 
positively related. However, extant findings on the mean-variance relationship appear three branches. French et al. (1987), Baillie and DeGennaro (1990), Campbell and Hentschel (1992), Scruggs (1998), Ghysels et al. (2005), Guo and Whitelaw (2006), Ludvigson and Ng (2007), Lundblad (2007), Pástor et al. (2008), Brandt and Wang (2010), and Rossi and Timmermann (2015), among others do find the risk-return tradeoff despite some less significant evidence. On the other hand, Campbell (1987), Nelson (1991), Whitelaw (1994), Brandt and Kang (2004), Lettau and Ludvigson (2010), Baker et al. (2011), Fiore and Saha (2015), and Booth et al. (2016), among others, document a negative mean-variance relationship. In addition, Turner et al. (1989), Glosten et al. (1993), Harvey (2001), Sun et al. (2017), and Wang et al. (2017), among others, report both positive and negative relationship between risk and returns. Ghysels et al. (2005) ascribe such inconsistency to different approaches to filter the unobservable conditional variance.

Behavior financial theories highlight investor sentiment in influencing stock prices, despite the traditional ones positing that stock prices are the discounted future cash flows and arbitrage leaves little space for investor sentiment (Fama, 1965). De Long et al. (1990) argue that sentiment investors trading together brings systematic risk into stock markets. The risk originated from the stochastic shifts in investor sentiment imposes arbitrage limits on rational investors, impeding them from trading against noise investors. In this sense, the mispricing caused by sentiment investors is persistent. Likewise, Baker and Wurgler (2006) ascribe the persistent sentiment-led mispricing to (1) uninformed demand shocks, and (2) limits on arbitrage. Uninformed demand shocks persist naturally as irrational investors' misbeliefs can be further strengthened by others 'joining on the bandwagon' (Brown and Cliff, 2005, p. 407). Limits on arbitrage hinder rational investors from relieving sentiment impact because they are normally subject to restricted investment horizons and can hardly accurately forecast how long the impact will persist (Shleifer and Vishny, 1997). Thus, a high level of optimism (pessimism) would commonly result in high (low) concurrent returns. Since each mispricing deviated from the intrinsic value should be finally 
reverted, the overpricing (underpricing) is then normally followed by low (high) subsequent returns. Ensuing empirical evidence supports the theoretical analyses in the US and global stock markets (Baker and Wurgler, 2006, 2007; Lemmon and Portniaguina, 2006; Schmeling, 2009; Da et al., 2011, 2015). However, the sentiment-return relationship does not hold in every stock market across the globe in that Schmeling (2009) detects some exceptions from developed stock markets and therefore confirms such relationship to be 'country-specific' (p. 400).

Above-mentioned two schools of literature come from two financial camps - traditional and behavioral. Yu and Yuan (2011) combine these by surveying the impact of investor sentiment on the mean-variance relationship. They hold that since initialing short positions is more complex than purchasing shares in stock markets given the short sale constraints (Barber and Odean, 2008; Karlsson et al., 2009; Antoniou et al., 2016), uninformed investors are less willing to trade over LSPs, indicating a lower degree of investor participation over LSPs. As uninformed individual investors are likely to misestimate the risk, their high level of participation over HSPs would distort the risk-return tradeoff. In line with the theoretical analysis, Yu and Yuan (2011) document the risk-return tradeoff over LSPs, rather than over HSPs.

\section{Data}

\subsection{Stock markets}

We sample 14 developed European stock markets. Return data are sourced from DataStream Total Market Equity Index that reflects the overall performance of one specific market. The sample sizes vary across markets due to data availability and all end in December 2016. Table 1 displays summary statistics of the monthly stock excess returns and realized volatility computed from within-month daily stock returns.

All markets yield positive monthly returns over the sample periods. Interestingly, stock returns do not necessarily show the leptokurtosis as widely documented in the literature (Lux, 1998). 
However, Lux (1998) reveals that high kurtosis is 'reduced under time aggregation' (p. 160), signifying that leptokurtosis becomes less evident when the data proceed from high to low frequency. It is, therefore, reasonable to observe platykurtic stock returns at the monthly interval. The mean of realized variance is, by definition, close to the variance of stock returns and the difference between two figures lies in Jensen's inequality (Ghysels et al., 2005). Consistently, the variance of stock returns is positively skewed and leptokurtosis across all stock markets.

\subsection{Investor sentiment}

We use the consumer confidence index (CCI) to proxy the elusive investor sentiment reflecting investors' subjective belief. As we separate the entire sample of each stock market based on the level of investor sentiment in empirical analyses, the investor sentiment proxy should provide long enough data so that we can have both samples over HSPs and LSPs in each market. CCIs offer such widely accessible data with plausibly long periods. ${ }^{1}$ Summary statistics of CCIs appear in the rest part of Table 1 .

We report the Spearman correlation in Table 2 to check whether CCIs across markets exhibit synchronous trends. The correlation varies from -0.145 (Germany and Norway) to 0.820 (Ireland and Spain), with the average of 0.369 , indicating that while our sample markets enjoy similarities in geographical location and economic development, investor sentiment across boarders does not necessarily move together.

\footnotetext{
${ }^{1}$ See Appendix for more details about proxies for investor sentiment.
} 
Table 1. Summary statistics of monthly excess stock returns, realized volatility, and consumer confidence

\begin{tabular}{|c|c|c|c|c|c|c|c|c|c|c|c|c|c|c|c|c|}
\hline \multirow[b]{2}{*}{ Market } & \multirow[b]{2}{*}{ From } & \multicolumn{4}{|c|}{ Excess stock returns (I) } & \multicolumn{4}{|c|}{ Realized volatility (II) } & \multicolumn{7}{|c|}{ Consumer confidence (III) } \\
\hline & & $\boldsymbol{\mu}$ & $\sigma^{2}$ & Skew. & Kurt. & $\mu$ & $\sigma^{2}$ & Skew. & Kurt. & Source & $\mu$ & $\sigma$ & $\operatorname{Max}$. & Min. & HSP & LSP \\
\hline Austria & 96.10 & 29 & 0.29 & -1.19 & 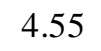 & 28 & 0.23 & 6.72 & 61.74 & Oesterreichische Nationalba & -2.14 & 8.19 & 16.00 & -23.00 & 8 & 13 \\
\hline Belgium & 1989.11 & 0.25 & 0.22 & -1.01 & 3.61 & .23 & 0.11 & 4.60 & 30.56 & National Bank of Belgium & -6.73 & 8.60 & 16.00 & -26.00 & 6 & 22 \\
\hline Denmark & 1992.04 & 0.64 & 0.27 & -0.45 & 1.34 & 0.26 & 0.17 & 8.11 & 92.78 & DG ECFIN* & 8.94 & 6.69 & 21.90 & -8.20 & 22 & 3 \\
\hline France & 1987.01 & 0.27 & 0.29 & -0.39 & 1.15 & 0.32 & 0.18 & 4.71 & 32.75 & National Institute for Statistics and Economic Studies & 101.20 & 10.31 & 129.50 & 79.81 & 17 & 13 \\
\hline Germany & 1986.01 & 0.24 & 0.30 & -0.69 & 1.86 & 0.30 & 0.20 & 7.76 & 94.53 & DG ECFIN & -7.28 & 9.14 & 10.90 & -32.90 & 6 & 25 \\
\hline Ireland & 1986.01 & 0.46 & 0.37 & -0.66 & 2.68 & 0.33 & 0.27 & 5.24 & 36.03 & DG ECFIN & -12.64 & 17.26 & 21.20 & -59.80 & 7 & 24 \\
\hline Italy & 1993.04 & 0.17 & 0.37 & 0.25 & 0.69 & 0.41 & 0.23 & 4.24 & 27.78 & National Institute of Statistics & 101.24 & 7.96 & 118.40 & 82.40 & 14 & 10 \\
\hline Luxembourg & 2003.01 & 0.55 & 0.16 & -0.49 & 1.75 & 0.20 & 0.04 & 4.00 & 27.70 & DG ECFIN & -0.95 & 6.66 & 13.40 & -20.70 & 6 & 8 \\
\hline Netherlands & 1987.04 & 0.27 & 0.26 & -1.14 & 3.34 & 0.29 & 0.22 & 4.87 & 33.46 & CBS - Statistics Netherlands & -6.57 & 17.16 & 27.00 & -44.00 & 12 & 18 \\
\hline Norway & 1993.08 & 0.44 & 0.34 & -0.92 & 2.78 & 0.40 & 0.43 & 5.93 & 45.62 & KANTAR TNS & 17.46 & 14.08 & 35.70 & -20.82 & 22 & 2 \\
\hline Spain & 1992.01 & 0.35 & 0.32 & -0.22 & 0.40 & 0.35 & 0.17 & 4.35 & 29.24 & DG ECFIN & -13.97 & 11.38 & 5.60 & -47.80 & 3 & 22 \\
\hline Sweden & 1994.01 & 0.61 & 0.35 & -0.28 & 1.17 & 0.45 & 0.28 & 3.02 & 12.19 & National Institute of Economic Research & 96.42 & 13.87 & 121.50 & 45.60 & 10 & 13 \\
\hline Switzerland & 1973.11 & 0.26 & 0.19 & -0.79 & 3.06 & 0.19 & 0.11 & 6.23 & 54.32 & State Secretariat for Economic Affairs & -8.54 & 18.58 & 25.30 & -53.60 & 15 & 29 \\
\hline UK & 1986.01 & 0.17 & 0.20 & -0.89 & 3.58 & 0.23 & 0.14 & 6.44 & 55.99 & DG ECFIN & -8.89 & 8.78 & 7.60 & -35.20 & 3 & 28 \\
\hline
\end{tabular}

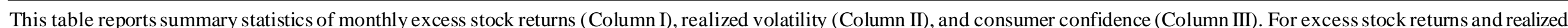

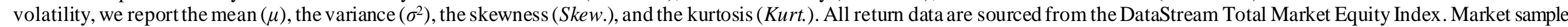

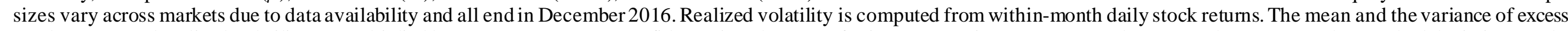

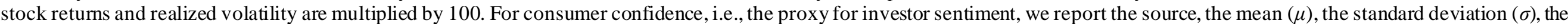
maximum and minimum values (Max. and Min.), and the number of years classified to HSPs and LSPs, based on the absolute reference approach (ARA).

* represents the Directorate General for Economic and Financial Affairs. 
Table 2. Spearman correlation

\begin{tabular}{|c|c|c|c|c|c|c|c|c|c|c|c|c|c|c|}
\hline & AUS & BEL & DEN & FRA & GER & IRE & ITA & LUX & NET & NOR & SPA & SWD & SWZ & UK \\
\hline \multicolumn{15}{|l|}{ AUS } \\
\hline BEL & 0.674 & & & & & & & & & & & & & \\
\hline DEN & 0.095 & 0.333 & & & & & & & & & & & & \\
\hline FRA & 0.489 & 0.587 & -0.010 & & & & & & & & & & & \\
\hline GER & 0.391 & 0.592 & 0.359 & 0.144 & & & & & & & & & & \\
\hline IRE & -0.046 & 0.419 & 0.400 & 0.394 & 0.150 & & & & & & & & & \\
\hline ITA & 0.207 & 0.556 & 0.231 & 0.660 & 0.267 & 0.607 & & & & & & & & \\
\hline LUX & 0.474 & 0.731 & 0.264 & 0.592 & 0.373 & 0.346 & 0.418 & & & & & & & \\
\hline NET & 0.287 & 0.571 & 0.385 & 0.591 & 0.441 & 0.671 & 0.747 & 0.559 & & & & & & \\
\hline NOR & 0.322 & 0.021 & 0.343 & 0.100 & -0.145 & 0.109 & -0.144 & 0.237 & 0.202 & & & & & \\
\hline SPA & 0.082 & 0.601 & 0.355 & 0.571 & 0.315 & 0.820 & 0.776 & 0.515 & 0.715 & -0.024 & & & & \\
\hline SWE & 0.726 & 0.657 & 0.274 & 0.290 & 0.463 & 0.174 & 0.194 & 0.525 & 0.283 & 0.039 & 0.292 & & & \\
\hline SWZ & 0.598 & 0.668 & 0.374 & 0.283 & 0.782 & 0.133 & 0.265 & 0.362 & 0.482 & -0.031 & 0.372 & 0.632 & & \\
\hline UK & -0.110 & 0.329 & 0.533 & 0.169 & 0.053 & 0.578 & 0.449 & 0.331 & 0.391 & 0.085 & 0.714 & 0.310 & 0.218 & \\
\hline
\end{tabular}

This table reports the pairwise Spearman correlation between CCIs across all markets. Coefficients in bold denote statistical significance at the $10 \%$ level or greater. 


\subsection{HSPS and LSPS}

Following Yu and Yuan (2011) and Antoniou et al. (2016), we define HSPs and LSPs as follows. One HSP or LSP needs to be at least one year to avoid frequent conversion between two regimes. ${ }^{2}$ We compute the annual investor sentiment in calendar year $T$ by averaging the monthly or quarterly CCIs within the calendar year $T$ : If it is higher (lower) than the NV, the next calendar year $(T+1)$ is then grouped into HSPs (LSPs). To distinguish this segregation criterion from other two explored later in Subsection 5.4, we denote it as the absolute reference approach (ARA). Note that consumer confidence indices are only for identification of HSPs and LSPs; as a result, no further techniques are required to keep frequency consistency. We also report the number of years for HSPs and LSPs in Table 1.

\section{Methodology}

As mentioned in Section 2, the extant empirical evidence does not reach the conclusion on the mean-variance relationship due to the choice of the volatility models. We, thus, measure conditional variance via four models including the RW, GARCH, GJR-GARCH, and EGARCH models.

\subsection{Rolling window model}

The RW model is a simple approach in measuring volatility of stock returns as it generates volatility series based on the realized variance, following the form,

$$
\operatorname{Var}_{t}\left(R_{t+1}\right)=\sigma_{t}^{2}=\frac{22}{N_{t}} \sum_{d=1}^{N_{t}} r_{t-d}^{2},
$$

\footnotetext{
${ }^{2} \mathrm{Yu}$ and Yuan (2011) and Antoniou et al. (2016) adopt the annual BW index from Baker and Wurgler (2006), which signifies that the minimum length of one regime to be at least one year.
} 
where $\operatorname{Var}_{t}\left(R_{t+1}\right)$ is the conditional variance for predicting the next-month stock returns $R_{t+1} ; \sigma_{t}^{2}$ is the realized volatility in month $t ; r_{t-d}$ is the demeaned daily stock return in month $t$, computed by subtracting the within-month mean daily return from the daily raw returns; $N_{t}$ is the actual number of trading days in month $t$ and 22 is the conventionally used number of trading days in one month.

\subsection{GARCH, GJR-GARCH, and EGARCH models}

GARCH-family models are widely used in capturing conditional volatility in stock markets. We select three GARCH-family models including GARCH, GJR-GARCH, and EGARCH (Engle, 1982; Bollerslev, 1986; Glosten et al., 1993; Nelson, 1991), with the last two accounting for the leverage effect that bad news introduces higher volatility than good news (Glosten et al., 1993). We first compute daily conditional volatility within each month based on the daily stock returns. The mean equation for all three GARCH models follows,

$$
r_{t+1}=\mu+\varepsilon_{t+1},
$$

where $r_{t+1}$ is the stock daily return at day $(t+1) ; \mu$ is the conditional mean of the stock daily return; $\varepsilon_{t+1}$ is the difference between realized daily stock returns and the conditional mean. We filter the daily conditional volatility of stock returns, following,

$$
\begin{aligned}
& \sigma_{t+1}^{2}=\omega+\alpha \varepsilon_{t}^{2}+\beta \sigma_{t}^{2}, \\
& \sigma_{t+1}^{2}=\omega+\alpha_{1} \varepsilon_{t}^{2}+\alpha_{2} I_{t} \varepsilon_{t}^{2}+\beta \sigma_{t}^{2}, \\
& \sigma_{t+1}^{2}=\exp \left\{\omega+\alpha_{1}\left[\operatorname{abs}\left(\varepsilon_{t}\right) / \operatorname{sqrt}\left(\sigma_{t}^{2}\right)\right]+\alpha_{2}\left[\varepsilon_{t} / \operatorname{sqrt}\left(\sigma_{t}^{2}\right)\right]+\beta \ln \sigma_{t}^{2}\right\},
\end{aligned}
$$

for GARCH, GJR-GARCH, and EGARCH models, respectively. The term $I_{t}$ in Eq. (4) is a dummy variable for good news to account for the leverage effect. We store daily conditional volatility series from three models and fit it to the specification below, 


$$
\operatorname{Var}_{t}\left(R_{t+1}\right)=E_{t}\left(\sum_{d=1}^{22} \sigma_{t+d}^{2}\right)
$$

where the monthly conditional volatility is computed by the linear sum of the daily conditional volatility, as suggested in Engle (2001) and Corsi (2009).

\subsection{Mean-variance relationship}

A direct test for the mean-variance relationship is as follows,

$$
R_{t+1}=\alpha+\beta \operatorname{Var}_{t}\left(R_{t+1}\right)+\xi_{t+1},
$$

where $R_{t+1}$ is the monthly stock returns at month $(t+1)$ and $\operatorname{Var}_{t}\left(R_{t+1}\right)$ is the conditional volatility computed from the aforementioned four approaches. To discriminate the mean-variance relationship over HSPs and LSPs, we estimate the following,

$$
R_{t+1}=\alpha_{1}+\alpha_{2} D_{t}+\beta_{1} \operatorname{Var}_{t}\left(R_{t+1}\right)+\beta_{2} D_{t} \operatorname{Var}_{t}\left(R_{t+1}\right)+\xi_{t+1},
$$

where $D_{t}$ is the dummy variable for HSPs, i.e., $D_{t}=1$ over HSPs while $D_{t}=0$ over LSPs. The estimation of $\beta_{1}$ represents the mean-variance relationship over LSPs, and $\left(\beta_{1}+\beta_{2}\right)$ represents the mean-variance over HSPs. If $\beta_{1}$ is significantly positive (negative), the mean-variance relationship over LSPs is positive (negative); likewise, if $\left(\beta_{1}+\beta_{2}\right)$ is significantly positive (negative), the meanvariance relationship over HSPs is positive (negative).

We hypothesize that over HSPs, the individual investors' increased participation would make the risk-return tradeoff less pronounced than that over LSPs, i.e., $\beta_{2}$ is significantly negative. Unlike Yu and Yuan (2011) positing that the mean-variance relationship should be positive over LSPs (i.e., $\beta_{1}$ is positive in our specification), we hypothesize in this way because we think while the individual investors' participation would be lower over LSPs than HSPs, it does not guarantee that such lower participation would cause no impact on the mean-variance relationship. In addition, we 
construct the panel dataset including 14 stock markets, across which investors are naturally heterogeneous. Therefore, expecting the risk-return tradeoff over LSPs would be unrealistic.

\section{Empirical results}

This section presents results on the mean-variance relationship. Subsection 5.1 reports the results from panel regressions, followed by findings from an indirect test in Subsection 5.2. Subsection 5.3 explores further at the individual market level, and finally, Subsection 5.4 discusses two more segregations adopted to classify HSPs and LSPs.

\subsection{Results for panel dataset}

We start with panel regressions by directly testing the mean-variance relationship and report the results in Table 3. The indiscriminate results show a negative mean-variance relationship in European stock markets, the results of which are consistent across four volatility models. The sensitivity varies from $-1.062(\mathrm{EGARCH})$ to $-0.798(\mathrm{GARCH})$. For instance, the GARCH model suggests that a $1 \%$ upward (downward) revision in conditional volatility is associated with a $0.798 \%$ decrease (increase) in stock returns. We also run regressions based on the balanced panel dataset dated from January 2003 to avoid our results being driven by markets having considerably longer periods. Clearly, the negative mean-variance relationship, ranging from -1.768 (EGARCH) to $-1.282(\mathrm{GARCH})$, is not distorted, with larger magnitude, though. 
Table 3. Panel results: Monthly excess returns against conditional variances

\begin{tabular}{|c|c|c|c|c|c|c|}
\hline \multirow[b]{2}{*}{ Method } & \multicolumn{2}{|c|}{ Whole sample (I) } & \multicolumn{4}{|c|}{ HSP/LSP (II) } \\
\hline & $\boldsymbol{\beta}$ & prob. & $\beta_{1}$ & prob. & $\boldsymbol{\beta}_{2}$ & prob. \\
\hline \multicolumn{7}{|c|}{ Panel A Unbalanced dataset } \\
\hline RW & -0.971 & $(0.000)^{\mathrm{a}}$ & -0.246 & $(0.352)$ & -1.142 & $(0.000)^{a}$ \\
\hline GARCH & -0.798 & $(0.000)^{\mathrm{a}}$ & 0.056 & $(0.854)$ & -1.324 & $(0.000)^{2}$ \\
\hline GJR-GARCH & -0.848 & $(0.000)^{\mathrm{a}}$ & -0.040 & $(0.891)$ & -1.259 & $(0.000)^{2}$ \\
\hline EGARCH & -1.062 & $(0.000)^{\mathrm{a}}$ & -0.049 & $(0.890)$ & -1.601 & $(0.000)^{a}$ \\
\hline \multicolumn{7}{|c|}{ Panel B Balanced dataset } \\
\hline RW & -1.376 & $(0.000)^{\mathrm{a}}$ & -0.751 & $(0.018)^{\mathrm{b}}$ & -1.115 & $(0.003)$ \\
\hline GARCH & -1.282 & $(0.000)^{\mathrm{a}}$ & -0.394 & $(0.286)$ & -1.444 & $(0.001)$ \\
\hline GJR-GARCH & -1.342 & $(0.000)^{\mathrm{a}}$ & -0.480 & $(0.184)$ & -1.350 & $(0.000)^{2}$ \\
\hline EGARCH & -1.768 & $(0.000)^{\mathrm{a}}$ & -0.566 & $(0.200)$ & -1.942 & $(0.000)$ \\
\hline
\end{tabular}

This table reports panel results from the panel dataset pooling all 14 European stock markets by assessing the relationship between excess returns and conditional variance. Column (I) presents the indiscriminate results from the whole sample, by estimating,

$$
R_{t+1}=\alpha+\beta \operatorname{Var}_{t}\left(R_{t+1}\right)+\xi_{t+1}
$$

where $R_{t+1}$ is the excess stock returns, and $\operatorname{Var}_{t}\left(R_{t+1}\right)$ is the conditional volatility computed from four different approaches: the RW and three GARCH-family models including GARCH, GJR-GARCH, and EGARCH models. Column (II) presents the results conditional on HSPs and LSPs. The separation criterion follows Yu and Yuan (2011) and Antoniou et al. (2016): One HSP or LSP needs to be at least one year to avoid frequent conversion between two regimes. We compute the annual investor sentiment in calendar year $T$ by averaging the monthly or quarterly CCIs within the calendar year $T$ : If it is higher (lower) than the NV, the next calendar year $(T+1)$ is then grouped into HSPs (LSPs). The regression specification is,

$$
R_{t+1}=\alpha_{1}+\alpha_{2} D_{t}+\beta_{1} \operatorname{Var}_{t}\left(R_{t+1}\right)+\beta_{2} D_{t} \operatorname{Var}_{t}\left(R_{t+1}\right)+\xi_{t+1} \text {, }
$$

where $D_{t}$ is the dummy variable for HSPs - that is $D_{t}=1$ over HSPs while $D_{t}=0$ over LSPs. Panel A presents results from the unbalanced dataset and Panel B presents results from the balanced data dating from January 2003 to avoid the strong impact of markets with considerably longer periods of data.

${ }^{\mathrm{a}}$ and ${ }^{\mathrm{b}}$ represent statistical significance at the $1 \%$ and $5 \%$ level, respectively. 
We then focus on the role of investor sentiment in the mean-variance relationship. Over LSPs, we do not reveal any risk-return tradeoff except for an insignificantly one generated in the GARCH model $\left(\beta_{1}=0.056\right)$. Over HSPs, however, such relationship becomes significantly negative, from $-1.650(-0.049-1.601$, EGARCH$)$ to $-1.269(0.056-1.324$, GARCH). For example, the GJRGARCH implies that a 1\% upward (downward) revision in conditional volatility causes a mildly $0.040 \%$ decrease (increase) in stock returns over LSPs, while a same movement leads to $1.299 \%$ decrease (increase) in stock returns over HSPs. The balanced dataset produces similar results that the mean-variance relationship over HSPs is more negative. The findings suggest individual investors to have stronger willingness to participate in trading over HSPs rather than LSPs, distorting the risk-return tradeoff due to their misestimation of market risk.

Yu and Yuan (2011) report the significantly positive mean-variance relationship over LSPs and the insignificant relationship over HSPs, which our results do not present. As mentioned in Section 2, Yu and Yuan (2011) use the composite BW index that is constructed on six market variables (Baker and Wurgler, 2006). This proxy reflects what the financial market is like and what investors do in the real world, i.e., ex post facts (Huang et al., 2015). However, our adoption of CCIs comes from consumer confidence surveys asking consumers' expectation for the future, i.e., ex ante predictions. Thus, there are discrepancies between their answers to sentiment surveys and their actual market behaviors. To reassure this conjecture, we compute the correlation between BW index and Michigan Consumer Sentiment Index (MCSI), spanning from January 1978 when the MCSI was firstly released at the monthly interval to September 2015 after which there is no public data available from Jeffrey Wurgler's website. ${ }^{3}$ The results are 0.3620 and 0.3624 between the MCSI and the raw BW index and between the MCSI and the orthogonalized BW index, respectively, both of which are not high. Note that our presented evidence is consistent with $\mathrm{Yu}$ and Yuan (2011) regarding the fact that over HSPs, higher levels of individual investors'

\footnotetext{
${ }^{3} \mathrm{We}$ are grateful to Jeffery Wurgler for making the data available at $\mathrm{http}: / /$ people.stern.nyu.edu/jwurgler.
} 
participation undermine the risk-return tradeoff and thus make the more negative (less positive) mean-variance relationship.

In general, we are unable to provide the significant risk-return tradeoff over LSPs, but find that increases in individual investors' participation over HSPs is likely to drive more pronounced negative mean-variance relationship, confirming investors' unsophistication and hence the impact of their participation on such relationship.

\subsection{An indirect test}

French et al. (1987) provide an indirect test of the risk-return tradeoff by assessing the relationship between realized returns and concurrent volatility innovations. If the risk-return tradeoff exists, i.e., high conditional volatility predicts low current prices and high expected returns, then the volatility innovation is likely to forecast low realized return. This implies a negative relationship between realized returns and concurrent volatility innovations. The regression follows,

$$
R_{t+1}=\alpha_{1}+\alpha_{2} D_{t}+\beta_{1} \operatorname{Var}_{t}\left(R_{t+1}\right)+\beta_{2} D_{t} \operatorname{Var}_{t}\left(R_{t+1}\right)+\gamma_{1} \operatorname{Var}\left(R_{t+1}\right)^{i}+\gamma_{2} D_{t} \operatorname{Var}\left(R_{t+1}\right)^{i+\xi_{t+1}}
$$

where $\operatorname{Var}\left(R_{t+1}\right)^{i}$ is the volatility innovation, which is the unexpected changes in concurrent volatility. ${ }^{4}$ We expect $\gamma_{2}$ to be positive since the participation of noise traders weakens the riskreturn tradeoff. We compute the volatility innovation as,

$$
\begin{aligned}
& \operatorname{Var}\left(R_{t+1}\right)^{i}=\sigma_{t}^{2}-\sigma_{t-1}^{2}, \\
& \operatorname{Var}\left(R_{t+1}\right)^{i}=\operatorname{Var}_{t}\left(R_{t+1}\right)-\operatorname{Var}_{t-1}\left(R_{t+1}\right),
\end{aligned}
$$

for the RW and all three GARCH models, respectively. Table 4 presents the results.

\footnotetext{
${ }^{4}$ There are two ways defining the volatility innovation. The first is the unexpected changes in concurrent volatility and the second is the unexpected changes in future volatility. We employ the former for consistency purposes, since the RW model needs additional assumptions in computing the unexpected changes in future volatility, which potentially increases the risk of misspecification.
} 
There is always a negative relationship between realized returns and concurrent volatility innovations over LSPs, from-13.457 (EGARCH) to-6.887 (RW). Such relationship becomes less negative over HSPs, albeit there is no significant difference between two sentiment regimes as provided by the RW $\left(\gamma_{2}=0.870\right)$ and the GARCH $\left(\gamma_{2}=0.514\right)$ models. For the balanced panel dataset, the RW model seems to generate a significant difference between LSPs and HSPs $\left(\gamma_{2}=\right.$ 1.285). The presented evidence indirectly confirms the impact of investor sentiment on the meanvariance relationship. 
Table 4. Panel results: Monthly excess returns against volatility innovations

\begin{tabular}{|c|c|c|c|c|c|c|c|c|}
\hline Method & $\beta_{1}$ & prob. & $\boldsymbol{\beta}_{2}$ & prob. & $\gamma_{1}$ & prob. & $\gamma_{2}$ & prob. \\
\hline \multicolumn{9}{|c|}{ Panel A Unbalanced dataset } \\
\hline RW & -3.215 & $(0.000)^{\mathrm{a}}$ & -0.689 & $(0.024)^{\mathrm{b}}$ & -6.887 & $(0.000)^{\mathrm{a}}$ & 0.870 & $(0.238)$ \\
\hline GARCH & -2.322 & $(0.000)^{\mathrm{a}}$ & -1.017 & $(0.000)^{\mathrm{a}}$ & -7.789 & $(0.000)^{\mathrm{a}}$ & 0.514 & $(0.348)$ \\
\hline GJR-GARCH & -3.249 & $(0.000)^{\mathrm{a}}$ & -0.694 & $(0.027)^{\mathrm{b}}$ & -9.441 & $(0.000)^{\mathrm{a}}$ & 1.392 & $(0.003)^{\mathrm{a}}$ \\
\hline EGARCH & -4.046 & $(0.000)^{\mathrm{a}}$ & -0.964 & $(0.006)^{\mathrm{a}}$ & -13.457 & $(0.000)^{\mathrm{a}}$ & 2.235 & $(0.000)^{\mathrm{a}}$ \\
\hline \multicolumn{9}{|c|}{ Panel B Balanced dataset } \\
\hline RW & -3.249 & $(0.000)^{\mathrm{a}}$ & -0.635 & $(0.064)^{\mathrm{c}}$ & -6.798 & $(0.000)^{\mathrm{a}}$ & 1.285 & $(0.004)^{\mathrm{a}}$ \\
\hline GARCH & -2.520 & $(0.000)^{\mathrm{a}}$ & -1.031 & $(0.008)^{\mathrm{a}}$ & -7.690 & $(0.000)^{\mathrm{a}}$ & 0.890 & $(0.155)$ \\
\hline GJR-GARCH & -3.314 & $(0.000)^{\mathrm{a}}$ & -0.626 & $(0.096)^{\mathrm{c}}$ & -8.468 & $(0.000)^{\mathrm{a}}$ & 1.422 & $(0.010)^{\mathrm{a}}$ \\
\hline EGARCH & -4.137 & $(0.000)^{\mathrm{a}}$ & -1.069 & $(0.014)^{\mathrm{b}}$ & -12.011 & $(0.000)^{\mathrm{a}}$ & 2.108 & $(0.003)^{\mathrm{a}}$ \\
\hline
\end{tabular}

This table reports panel results from the panel dataset pooling all 14 European stock markets by assessing the relationship between excess returns and volatility innovations. Presented results comes from,

$$
R_{t+1}=\alpha_{1}+\alpha_{2} D_{t}+\beta_{1} \operatorname{Var}_{t}\left(R_{t+1}\right)+\beta_{2} D_{t} \operatorname{Var}_{t}\left(R_{t+1}\right)+\gamma_{1} \operatorname{Var}\left(R_{t+1}\right)^{i}+\gamma_{2} D_{t} \operatorname{Var}\left(R_{t+1}\right)^{i}+\xi_{t+1},
$$

where $\operatorname{Var}\left(R_{t+1}\right)^{i}$ is the volatility innovation, which is the unexpected changes in concurrent volatility. For the RW and GARCH-family models, we compute the unexpected innovations in concurrent volatility, respectively,

$$
\begin{aligned}
& \operatorname{Var}\left(R_{t+1}\right)^{i}=\sigma_{t}^{2}-\sigma_{t-1}^{2}, \\
& \operatorname{Var}\left(R_{t+1}\right)^{i}=\operatorname{Var}_{t}\left(R_{t+1}\right)-\operatorname{Var}_{t-1}\left(R_{t+1}\right) .
\end{aligned}
$$

Results are conditional on HSPs and LSPs. The separation criterion follows Yu and Yuan (2011) and Antoniou et al. (2016): One HSP or LSP needs to be at least one year to avoid frequent conversion between two regimes. We compute the annual investor sentiment in calendar year $T$ by averaging the monthly or quarterly CCIs within the calendar year $T$ : If it is higher (lower) than the NV, the next calendar year $(T+1)$ is then grouped into HSPs (LSPs). $D_{t}$ is the dummy variable for HSPs - that is $D_{t}=1$ over HSPs while $D_{t}=0$ over LSPs. Panel A presents results from the unbalanced dataset and Panel B presents results from the balanced data dating from January 2003 to avoid the strong impact of markets with considerably longer periods of data.

a b, and ${ }^{\mathrm{c}}$ represent statistical significance at the $1 \%, 5 \%$, and $10 \%$ level, respectively. 


\subsection{Results for individual markets}

Table 5 presents results for individual markets. At the first glance, we notice quite some heterogeneity across markets. For the entire sample periods, only two markets consistently show the positive mean-variance relationship across four volatility models - Italy and Spain, with low significance, though. The rest 12 markets show the negative relationship and some of them are significant. For instance, a $1 \%$ upward (downward) revision in conditional volatility causes a $2.243 \%$ decrease (increase) in stock returns in Austria, and a $1.156 \%$ decrease (increase) in Switzerland, given by the RW model.

The heterogeneity persists after we separate the entire sample into LSPs and HSPs. While like results from the panel dataset, individual market results do not evidently exhibit the significant risk-return tradeoff except for Switzerland, over half markets present a more negative meanvariance relationship over HSPs and four of them are significant across all volatility modelsAustria, France, Germany, and Switzerland. For example, according to the GJR-GARCH, a $1 \%$ increase (decrease) in conditional variance in Switzerland would lead to a $2.593 \%$ increase (decrease) while a $1.589 \%(2.593 \%-4.182 \%)$ decrease (increase) in stock returns over LSPs and HSPs, respectively. However, three markets-Ireland, Spain, and the UK-show a different pattern, from which we see significantly positive estimations over HSPs.

Such variations in the impact of investor sentiment on the mean-variance relationship is, to some degree, reasonable, because investor sentiment per se differs in prevalence and influences across markets, as documented in Schmeling (2009). 
Table 5. Individual market results: Monthly excess returns against conditional variances

\begin{tabular}{|c|c|c|c|c|c|c|}
\hline \multirow[b]{2}{*}{ Market } & \multicolumn{2}{|c|}{ Whole sample (I) } & \multicolumn{4}{|c|}{ Absolute HSP/LSP (II) } \\
\hline & $\boldsymbol{\beta}$ & prob. & $\beta_{1}$ & prob. & $\boldsymbol{\beta}_{2}$ & prob. \\
\hline \multicolumn{7}{|c|}{ Panel A: Rolling window } \\
\hline Austria & -2.243 & $(0.002)^{\mathrm{a}}$ & 1.156 & $(0.485)$ & -3.903 & $(0.033)^{\mathrm{b}}$ \\
\hline Belgium & -2.263 & $(0.003)^{\mathrm{a}}$ & -2.640 & $(0.001)^{\mathrm{a}}$ & 2.982 & $(0.307)$ \\
\hline Denmark & -1.792 & $(0.013)^{\mathrm{b}}$ & -4.284 & $(0.640)$ & 2.419 & $(0.792)$ \\
\hline France & -0.670 & $(0.318)$ & 1.859 & $(0.261)$ & -3.004 & $(0.097)^{c}$ \\
\hline Germany & -0.611 & $(0.332)$ & 1.901 & $(0.081)^{\mathrm{c}}$ & -3.124 & $(0.020)^{\mathrm{b}}$ \\
\hline Ireland & -2.420 & $(0.000)^{\mathrm{a}}$ & -2.882 & $(0.000)^{\mathrm{a}}$ & 4.774 & $(0.017)^{\mathrm{b}}$ \\
\hline Italy & 0.272 & $(0.719)$ & 2.340 & $(0.237)$ & -2.189 & $(0.307)$ \\
\hline Luxembourg & -2.593 & $(0.105)$ & -0.743 & $(0.787)$ & -2.811 & $(0.406)$ \\
\hline Netherlands & -1.151 & $(0.044)^{\mathrm{b}}$ & 0.041 & $(0.968)$ & -1.629 & $(0.190)$ \\
\hline Norway & -0.682 & $(0.201)$ & -0.344 & $(0.946)$ & -0.328 & $(0.949)$ \\
\hline Spain & 0.628 & $(0.460)$ & 0.235 & $(0.777)$ & 5.363 & $(0.060)^{b}$ \\
\hline Sweden & 0.020 & $(0.976)$ & 1.859 & $(0.088)^{\mathrm{c}}$ & -2.708 & $(0.053)^{\mathrm{c}}$ \\
\hline Switzerland & -1.156 & $(0.039)^{\mathrm{b}}$ & 2.421 & $(0.033)^{b}$ & -4.117 & $(0.002)^{\mathrm{a}}$ \\
\hline UK & -0.592 & $(0.335)$ & -0.746 & $(0.231)$ & 5.228 & $(0.150)$ \\
\hline \multicolumn{7}{|c|}{ Panel B: GARCH } \\
\hline Austria & -1.812 & $(0.021)^{\mathrm{b}}$ & 2.516 & $(0.192)$ & -4.897 & $(0.020)^{\mathrm{b}}$ \\
\hline Belgium & -1.737 & $(0.051)^{\mathrm{c}}$ & -2.188 & $(0.016)^{\mathrm{b}}$ & 5.717 & $(0.162)$ \\
\hline Denmark & -2.178 & $(0.019)^{\mathrm{b}}$ & -6.114 & $(0.602)$ & 3.844 & $(0.744)$ \\
\hline France & -0.856 & $(0.301)$ & 2.395 & $(0.261)$ & -3.797 & $(0.091)^{c}$ \\
\hline Germany & -0.240 & $(0.770)$ & 1.847 & $(0.174)$ & -2.830 & $(0.058)^{\mathrm{c}}$ \\
\hline Ireland & -2.345 & $(0.001)^{\mathrm{a}}$ & -2.856 & $(0.000)^{\mathrm{a}}$ & 7.374 & $(0.010)^{b}$ \\
\hline Italy & 0.583 & $(0.506)$ & 2.485 & $(0.254)$ & -1.941 & $(0.415)$ \\
\hline Luxembourg & -2.890 & $(0.196)$ & -0.940 & $(0.808)$ & -2.952 & $(0.534)$ \\
\hline Netherlands & -0.703 & $(0.267)$ & -0.146 & $(0.900)$ & -0.671 & $(0.630)$ \\
\hline Norway & -0.401 & $(0.521)$ & -0.279 & $(0.968)$ & -0.105 & $(0.988)$ \\
\hline Spain & 1.099 & $(0.245)$ & 0.740 & $(0.446)$ & 7.611 & $(0.060)^{\mathrm{b}}$ \\
\hline Sweden & -0.477 & $(0.533)$ & 1.171 & $(0.356)$ & -2.321 & $(0.149)$ \\
\hline Switzerland & -1.089 & $(0.093)^{\mathrm{c}}$ & 3.102 & $(0.015)^{\mathrm{b}}$ & -4.833 & $(0.001)^{\mathrm{a}}$ \\
\hline UK & -0.196 & $(0.795)$ & -0.424 & $(0.578)$ & 8.557 & $(0.068)^{\mathrm{c}}$ \\
\hline \multicolumn{7}{|c|}{ Panel C: GJR-GARCH } \\
\hline Austria & -1.860 & $(0.015)^{\mathrm{b}}$ & 2.383 & $(0.216)$ & -4.742 & $(0.024)^{\mathrm{b}}$ \\
\hline Belgium & -1.865 & $(0.022)^{\mathrm{b}}$ & -2.156 & $(0.009)^{\mathrm{a}}$ & 3.627 & $(0.355)$ \\
\hline Denmark & -2.106 & $(0.020)^{\mathrm{b}}$ & -8.744 & $(0.452)$ & 6.571 & $(0.573)$ \\
\hline France & -0.896 & $(0.274)$ & 2.263 & $(0.287)$ & -3.682 & $(0.087)^{c}$ \\
\hline Germany & -0.279 & $(0.747)$ & 1.712 & $(0.178)$ & -2.733 & $(0.050)^{\mathrm{b}}$ \\
\hline Ireland & -2.312 & $(0.001)^{\mathrm{a}}$ & -2.751 & $(0.000)^{\mathrm{a}}$ & 6.152 & $(0.019)^{\mathrm{b}}$ \\
\hline Italy & 0.650 & $(0.455)$ & 2.750 & $(0.214)$ & -2.108 & $(0.382)$ \\
\hline Luxembourg & -2.778 & $(0.194)$ & -0.765 & $(0.847)$ & -2.841 & $(0.547)$ \\
\hline Netherlands & -0.784 & $(0.192)$ & -0.111 & $(0.927)$ & -0.784 & $(0.575)$ \\
\hline Norway & -0.434 & $(0.472)$ & 1.298 & $(0.860)$ & -1.721 & $(0.815)$ \\
\hline Spain & 1.245 & $(0.194)$ & 0.883 & $(0.377)$ & 6.358 & $(0.081)^{\mathrm{c}}$ \\
\hline Sweden & -0.501 & $(0.522)$ & 1.316 & $(0.331)$ & -2.457 & $(0.143)$ \\
\hline Switzerland & -1.108 & $(0.060)^{\mathrm{c}}$ & 2.593 & $(0.030)^{\mathrm{b}}$ & -4.182 & $(0.002)^{\mathrm{a}}$ \\
\hline UK & -0.149 & $(0.833)$ & -0.340 & $(0.633)$ & 8.214 & $(0.079)^{\mathrm{c}}$ \\
\hline
\end{tabular}


Table 5. (continued)

\begin{tabular}{|c|c|c|c|c|c|c|}
\hline \multirow[b]{2}{*}{ Market } & \multicolumn{2}{|c|}{ Whole sample (I) } & \multicolumn{4}{|c|}{ Absolute HSP/LSP (II) } \\
\hline & $\boldsymbol{\beta}$ & prob. & $\beta_{1}$ & prob. & $\boldsymbol{\beta}_{2}$ & prob. \\
\hline \multicolumn{7}{|c|}{ Panel D: EGARCH } \\
\hline Austria & -2.418 & $(0.011)^{\mathrm{b}}$ & 2.341 & $(0.290)$ & -5.450 & $(0.026)^{b}$ \\
\hline Belgium & -2.295 & $(0.023)^{\mathrm{b}}$ & -2.717 & $(0.008)^{\mathrm{a}}$ & 5.151 & $(0.254)$ \\
\hline Denmark & -2.758 & $(0.020)^{\mathrm{b}}$ & -10.582 & $(0.387)$ & 7.743 & $(0.529)$ \\
\hline France & -0.911 & $(0.387)$ & 2.256 & $(0.354)$ & -3.857 & $(0.094)^{c}$ \\
\hline Germany & -0.450 & $(0.686)$ & 1.565 & $(0.308)$ & -2.339 & $(0.097)^{\mathrm{c}}$ \\
\hline Ireland & -2.825 & $(0.002)^{\mathrm{a}}$ & -3.404 & $(0.000)^{\mathrm{a}}$ & 7.670 & $(0.024)$ \\
\hline Italy & 0.766 & $(0.477)$ & 2.625 & $(0.289)$ & -1.742 & $(0.528)$ \\
\hline Luxembourg & -3.675 & $(0.142)$ & -0.347 & $(0.933)$ & -5.264 & $(0.312)$ \\
\hline Netherlands & -0.922 & $(0.211)$ & -0.169 & $(0.896)$ & -0.963 & $(0.543)$ \\
\hline Norway & -0.535 & $(0.489)$ & 2.380 & $(0.741)$ & -2.933 & $(0.685)$ \\
\hline Spain & 1.320 & $(0.260)$ & 0.934 & $(0.445)$ & 7.944 & $(0.085)^{\mathrm{c}}$ \\
\hline Sweden & -0.865 & $(0.330)$ & 1.198 & $(0.421)$ & -2.892 & $(0.123)$ \\
\hline Switzerland & -1.557 & $(0.049)^{b}$ & 2.618 & $(0.077)^{\mathrm{c}}$ & -4.837 & $(0.006)^{\mathrm{a}}$ \\
\hline UK & -0.089 & $(0.923)$ & -0.397 & $(0.674)$ & 8.062 & $(0.096)^{\mathrm{c}}$ \\
\hline
\end{tabular}

This table reports panel results from 14 individual European stock markets by assessing the relationship between excess returns and conditional variance. Column (I) presents the indiscriminate results from the whole sample, by estimating,

$$
R_{t+1}=\alpha+\beta \operatorname{Var}_{t}\left(R_{t+1}\right)+\xi_{t+1},
$$

where $R_{t+1}$ is the excess stock returns, and $\operatorname{Var}_{t}\left(R_{t+1}\right)$ is the conditional volatility computed from four different approaches: the RW and three GARCH-family models including GARCH, GJR-GARCH, and EGARCH models. Column (II) presents the results conditional on HSPs and LSPs. The separation criterion follows Yu and Yuan (2011) and Antoniou et al. (2016): One HSP or LSP needs to be at least one year to avoid frequent conversion between two regimes. We compute the annual investor sentiment in calendar year $T$ by averaging the monthly or quarterly CCIs within the calendar year $T$ : If it is higher (lower) than the NV, the next calendar year $(T+1)$ is then grouped into HSPs (LSPs). The regression specification is,

$$
R_{t+1}=\alpha_{1}+\alpha_{2} D_{t}+\beta_{1} \operatorname{Var}_{t}\left(R_{t+1}\right)+\beta_{2} D_{t} \operatorname{Var}_{t}\left(R_{t+1}\right)+\xi_{t+1},
$$

where $D_{t}$ is the dummy variable for HSPs - that is $D_{t}=1$ over HSPs while $D_{t}=0$ over LSPs. Panel A, B, C, and D presents results from the RW, GARCH, GJR-GARCH, and EGARCH models, accordingly.

${ }^{\mathrm{a}}$ b $^{\mathrm{b}}$, and ${ }^{\mathrm{c}}$ represent statistical significance at the $1 \%, 5 \%$, and $10 \%$ level, respectively. 


\subsection{Two more HSP/LSP segregation criteria}

As shown in Table 1, while all our 14 sample markets present both HSPs and LSPs, the lengths of two periods in some markets are severely unevenly distributed, exemplified by Denmark, Norway, Spain, and the UK. In addition to the statistical concern that fewer numbers of observations may provide weaker results, this uneven distribution may raise another issue - the segregation based on the NVs probably neglect some important implications conveyed by investors answering to the sentiment surveys.

Since investors in different markets may have different degrees of optimism and pessimism, objective NVs denoting investors to be neither optimistic nor pessimistic may lose its meaning if investors in one market naturally (or genetically) incline to be optimistic or pessimistic. For example, German investors are classified as 'bearish' if the sentiment survey reports the index of -1.00 . However, they can behave bullishly in stock trading because -1.00 is higher than the allperiod average value, -7.28 (see, Table 1), suggesting that individuals are bullish in the relative sense. Conversely, if the CCI in Norway is 1.00 , investors are optimistic in relation to the NV. However, they may behave bearishly as the all-period average of their sentiment level is as high as 17.46 (see, Table 1). It implies that whether investors are truly optimistic (pessimistic) may depend more on their sentiment level relative to the normal state, rather than NVs set by sentiment surveys.

This concern is particularly evident in our sample since we collect CCIs for half of our markets from the single source-Directorate General for Economic and Financial Affairs (see, Table 1), which largely increases the risk of the misuse of the uniform NV across several stock markets. Except for Luxembourg, the rest 6 markets tend to present comparatively longer HSPs or LSPs. In fact, using domestic CCI surveys does not necessarily address this potential problem in that these surveys are conducted in an objective manner - if consumers respond to survey questions in a 
bullish (bearish) way, there is no further adjustment to reflect the real sentiment based on their normal sentiment level.

Considering these points, we conjecture that the nominal CCIs do not fully reveal investors' bullishness or bearishness and thus their willingness to trade in stock markets. Instead, what matters is their relative sentiment level to their normal sentiment state. To confirm this, we propose two new segregation criteria based on investors' normal sentiment state - the relative reference approach (RRA) and the moving-average reference approach (MRA). For the RRA, we first calculate the average of the CCI in each stock market over all periods and regard it as the relative reference value, or in other words, the normal sentiment state. We then compare the average CCI in calendar year $T$ with the whole-period average CCI: If the former is higher (lower), the next calendar year $(T+1)$ is identified as the HSP (LSP). For MRA, we first calculate the past threeyear average of the CCI in each stock market from year $(T-3)$ to year $(T-1)$. We replicate the above comparison: If the average CCI in calendar year $T$ is higher (lower), the next calendar year $(T+1)$ is categorized as the HSP (LSP).

The only difference between the RRA and the MRA lies in the fact that the former considers a longer period than the latter. The RRA reflects the normal sentiment level in one market by considering the all-period investors' dispositions and characteristics. MRA offers a more dynamic and updating view. We replicate the previous tests and report the results of all markets and individual markets in Table 6 and 7, respectively. 
Table 6. Panel results: Conditional on RRA and MRA

\begin{tabular}{|c|c|c|c|c|c|c|c|c|}
\hline \multirow[b]{2}{*}{ Method } & \multicolumn{4}{|c|}{ Relative HSP/LSP (I) } & \multicolumn{4}{|c|}{ Moving HSP/LSP (II) } \\
\hline & $\beta_{1}$ & prob. & $\boldsymbol{\beta}_{2}$ & prob. & $\beta_{1}$ & prob. & $\boldsymbol{\beta}_{2}$ & prob. \\
\hline \multicolumn{9}{|c|}{ Panel A Unbalanced dataset } \\
\hline RW & 0.722 & $(0.022)^{\mathrm{b}}$ & -2.145 & $(0.000)^{\mathrm{a}}$ & 0.047 & $(0.870)$ & -1.283 & $(0.001)^{\mathrm{a}}$ \\
\hline GARCH & 1.247 & $(0.000)^{\mathrm{a}}$ & -2.562 & $(0.000)^{\mathrm{a}}$ & 0.071 & $(0.826)$ & -1.183 & $(0.001)^{\mathrm{a}}$ \\
\hline GJR-GARCH & 1.135 & $(0.001)^{\mathrm{a}}$ & -2.446 & $(0.000)^{\mathrm{a}}$ & 0.027 & $(0.934)$ & -1.160 & $(0.001)^{\mathrm{a}}$ \\
\hline EGARCH & 1.298 & $(0.002)^{\mathrm{a}}$ & -2.931 & $(0.000)^{\mathrm{a}}$ & -0.030 & $(0.937)$ & -1.459 & $(0.000)^{\mathrm{a}}$ \\
\hline \multicolumn{9}{|c|}{ Panel B Balanced dataset } \\
\hline RW & 0.920 & $(0.011)^{\mathrm{b}}$ & -2.865 & $(0.000)^{\mathrm{a}}$ & -0.173 & $(0.618)$ & -1.650 & $(0.000)^{\mathrm{a}}$ \\
\hline GARCH & 1.331 & $(0.001)^{\mathrm{a}}$ & -3.245 & $(0.000)^{\mathrm{a}}$ & 0.179 & $(0.653)$ & -1.872 & $(0.000)^{\mathrm{a}}$ \\
\hline GJR-GARCH & 1.337 & $(0.002)^{\mathrm{a}}$ & -3.220 & $(0.000)^{\mathrm{a}}$ & 0.135 & $(0.737)$ & -1.801 & $(0.000)^{\mathrm{a}}$ \\
\hline EGARCH & 1.316 & $(0.007)^{\mathrm{a}}$ & -3.865 & $(0.000)^{\mathrm{a}}$ & 0.230 & $(0.636)$ & -2.494 & $(0.000)^{\mathrm{a}}$ \\
\hline
\end{tabular}

This table reports panel results from 14 individual European stock markets by assessing the relationship between excess returns and conditional variance. Results are conditional on HSPs and LSPs according to the relative reference approach (RRA, Column I) and the moving-average reference approach (MRA, Column II). For the RRA, we first calculate the average of the $\mathrm{CCI}$ in each stock market over all periods and regard it as the relative reference value, or in other words, the normal sentiment state. We then compare the average CCI in calendar year $T$ with the wholeperiod average CCI: If the former is higher (lower), the next calendar year $(T+1)$ is identified as the HSP (LSP). For MRA, we first calculate the past three-year average of the CCI in each stock market from year $(T-3)$ to year $(T$ $-1)$. We replicate the above comparison: If the average CCI in calendar year $T$ is higher (lower), the next calendar year $(T+1)$ is categorized as the HSP(LSP). The regression specification is,

$$
R_{t+1}=\alpha_{1}+\alpha_{2} D_{t}+\beta_{1} \operatorname{Var}_{t}\left(R_{t+1}\right)+\beta_{2} D_{t} \operatorname{Var}_{t}\left(R_{t+1}\right)+\xi_{t+1} \text {, }
$$

where $D_{t}$ is the dummy variable for HSPs - that is $D_{t}=1$ over HSPs while $D_{t}=0$ over LSPs. Panel A presents results from the unbalanced dataset and Panel B presents results from the balanced data dating from January 2003 to avoid the strong impact of markets with considerably longer periods of data.

${ }^{\mathrm{a}}$ and ${ }^{\mathrm{b}}$ represent statistical significance at the $1 \%$ and $5 \%$ level, respectively. 


\begin{tabular}{|c|c|c|c|c|c|c|c|c|}
\hline \multirow[b]{2}{*}{ Market } & \multicolumn{4}{|c|}{ Relative HSP/LSP (I) } & \multicolumn{4}{|c|}{ Moving HSP/LSP (II) } \\
\hline & $\beta_{1}$ & prob. & $\boldsymbol{\beta}_{2}$ & prob. & $\beta_{1}$ & prob. & $\boldsymbol{\beta}_{2}$ & prob. \\
\hline \multicolumn{9}{|c|}{ Panel A: Rolling window } \\
\hline Austria & 0.816 & $(0.626)$ & -3.537 & $(0.056)^{\mathrm{c}}$ & 1.460 & $(0.403)$ & -4.166 & $(0.029)^{\mathrm{b}}$ \\
\hline Belgium & 1.073 & $(0.500)$ & -3.823 & $(0.035)^{\mathrm{b}}$ & 1.258 & $(0.327)$ & -5.333 & $(0.001)^{\mathrm{a}}$ \\
\hline Denmark & -0.354 & $(0.846)$ & -1.610 & $(0.418)$ & -0.554 & $(0.800)$ & -1.380 & $(0.552)$ \\
\hline France & 1.489 & $(0.358)$ & -2.539 & $(0.155)$ & 2.180 & $(0.154)$ & -3.389 & $(0.047)^{b}$ \\
\hline Germany & 3.570 & $(0.047)^{\mathrm{b}}$ & -4.511 & $(0.019)^{\mathrm{b}}$ & 1.970 & $(0.160)$ & -3.054 & $(0.053)^{\mathrm{c}}$ \\
\hline Ireland & -1.662 & $(0.120)$ & -1.082 & $(0.400)$ & -2.658 & $(0.000)^{\mathrm{a}}$ & 2.196 & $(0.155)$ \\
\hline Italy & -0.808 & $(0.388)$ & 3.108 & $(0.051)^{\mathrm{c}}$ & 3.034 & $(0.131)$ & -2.854 & $(0.189)$ \\
\hline Luxembourg & -2.672 & $(0.453)$ & -0.149 & $(0.970)$ & -0.741 & $(0.820)$ & -0.863 & $(0.820)$ \\
\hline Netherlands & 1.736 & $(0.213)$ & -3.255 & $(0.034)^{\mathrm{b}}$ & 0.134 & $(0.900)$ & -1.542 & $(0.241)$ \\
\hline Norway & 0.569 & $(0.712)$ & -1.377 & $(0.402)$ & 1.141 & $(0.453)$ & -2.029 & $(0.215)$ \\
\hline Spain & 0.657 & $(0.660)$ & -0.048 & $(0.978)$ & -0.509 & $(0.603)$ & 3.220 & $(0.054)^{\mathrm{c}}$ \\
\hline Sweden & 3.112 & $(0.018)^{\mathrm{b}}$ & -3.878 & $(0.012)^{\mathrm{b}}$ & 1.554 & $(0.323)$ & -1.669 & $(0.344)$ \\
\hline Switzerland & 2.958 & $(0.047)^{\mathrm{b}}$ & -4.471 & $(0.005)^{\mathrm{a}}$ & 2.693 & $(0.045)^{\mathrm{b}}$ & -4.480 & $(0.002)^{\mathrm{a}}$ \\
\hline UK & -1.071 & $(0.316)$ & 0.851 & $(0.515)$ & -0.342 & $(0.622)$ & 3.737 & $(0.045)^{\mathrm{b}}$ \\
\hline \multicolumn{9}{|c|}{ Panel B: GARCH } \\
\hline Austria & 2.295 & $(0.239)$ & -4.686 & $(0.028)^{\mathrm{b}}$ & 2.431 & $(0.240)$ & -4.789 & $(0.032)^{\mathrm{b}}$ \\
\hline Belgium & 2.327 & $(0.236)$ & -4.461 & $(0.042)^{\mathrm{b}}$ & 1.320 & $(0.397)$ & -4.421 & $(0.019)^{\mathrm{b}}$ \\
\hline Denmark & -0.539 & $(0.828)$ & -1.779 & $(0.505)$ & -0.179 & $(0.952)$ & -2.190 & $(0.480)$ \\
\hline France & 1.852 & $(0.373)$ & -3.129 & $(0.168)$ & 2.520 & $(0.196)$ & -3.934 & $(0.069)^{\mathrm{c}}$ \\
\hline Germany & 4.465 & $(0.043)^{\mathrm{b}}$ & -5.069 & $(0.033)^{\mathrm{b}}$ & 1.729 & $(0.316)$ & -2.465 & $(0.214)$ \\
\hline Ireland & -0.444 & $(0.731)$ & -2.771 & $(0.077)^{\mathrm{c}}$ & -3.028 & $(0.001)^{\mathrm{a}}$ & 3.290 & $(0.110)$ \\
\hline Italy & -0.609 & $(0.562)$ & 3.840 & $(0.042)^{\mathrm{b}}$ & 2.772 & $(0.210)$ & -2.080 & $(0.389)$ \\
\hline Luxembourg & -1.398 & $(0.775)$ & -2.235 & $(0.685)$ & -3.681 & $(0.411)$ & 3.317 & $(0.527)$ \\
\hline Netherlands & 2.080 & $(0.197)$ & -3.028 & $(0.085)^{\mathrm{c}}$ & -0.139 & $(0.908)$ & -0.787 & $(0.591)$ \\
\hline Norway & 0.846 & $(0.646)$ & -1.359 & $(0.488)$ & 1.608 & $(0.382)$ & -2.183 & $(0.268)$ \\
\hline Spain & 1.643 & $(0.348)$ & -0.778 & $(0.708)$ & -0.336 & $(0.772)$ & 4.101 & $(0.039)^{\mathrm{b}}$ \\
\hline Sweden & 3.228 & $(0.033)^{\mathrm{b}}$ & -4.651 & $(0.008)^{\mathrm{a}}$ & 0.270 & $(0.878)$ & -0.696 & $(0.725)$ \\
\hline Switzerland & 3.343 & $(0.036)^{\mathrm{b}}$ & -4.889 & $(0.005)^{\mathrm{a}}$ & 3.243 & $(0.029)^{\mathrm{b}}$ & -5.045 & $(0.002)^{\mathrm{a}}$ \\
\hline UK & 0.451 & $(0.738)$ & -0.772 & $(0.636)$ & -0.543 & $(0.518)$ & 5.735 & $(0.013)^{\mathrm{b}}$ \\
\hline \multicolumn{9}{|c|}{ Panel C: GJR-GARCH } \\
\hline Austria & 2.151 & $(0.269)$ & -4.516 & $(0.033)^{\mathrm{b}}$ & 2.429 & $(0.260)$ & -4.754 & $(0.040)^{b}$ \\
\hline Belgium & 2.612 & $(0.197)$ & -4.759 & $(0.031)^{\mathrm{b}}$ & 1.005 & $(0.555)$ & -3.600 & $(0.063)^{\mathrm{c}}$ \\
\hline Denmark & -0.032 & $(0.990)$ & -2.207 & $(0.430)$ & 1.055 & $(0.745)$ & -3.361 & $(0.320)$ \\
\hline France & 1.765 & $(0.395)$ & -3.069 & $(0.175)$ & 2.155 & $(0.289)$ & -3.461 & $(0.121)$ \\
\hline Germany & 3.793 & $(0.073)^{\mathrm{c}}$ & -4.442 & $(0.055)^{\mathrm{c}}$ & 1.867 & $(0.246)$ & -2.971 & $(0.131)$ \\
\hline Ireland & -0.867 & $(0.460)$ & -2.140 & $(0.137)$ & -2.894 & $(0.001)^{\mathrm{a}}$ & 2.674 & $(0.165)$ \\
\hline Italy & -0.635 & $(0.548)$ & 3.919 & $(0.035)^{\mathrm{b}}$ & 3.027 & $(0.176)$ & -2.494 & $(0.355)$ \\
\hline Luxembourg & -1.498 & $(0.762)$ & -1.819 & $(0.741)$ & -3.080 & $(0.507)$ & 2.833 & $(0.593)$ \\
\hline Netherlands & 2.232 & $(0.193)$ & -3.198 & $(0.082)^{\mathrm{c}}$ & -0.076 & $(0.952)$ & -0.879 & $(0.551)$ \\
\hline Norway & 0.712 & $(0.717)$ & -1.210 & $(0.558)$ & 1.334 & $(0.492)$ & -1.894 & $(0.356)$ \\
\hline Spain & 2.054 & $(0.281)$ & -1.086 & $(0.622)$ & -0.127 & $(0.917)$ & 3.498 & $(0.076)^{\mathrm{c}}$ \\
\hline Sweden & 3.614 & $(0.029)^{\mathrm{b}}$ & -4.956 & $(0.009)^{\mathrm{a}}$ & 0.311 & $(0.869)$ & -0.777 & $(0.713)$ \\
\hline Switzerland & 2.897 & $(0.061)^{\mathrm{c}}$ & -4.311 & $(0.010)^{\mathrm{b}}$ & 2.614 & $(0.063)^{\mathrm{c}}$ & -4.234 & $(0.006)^{\mathrm{a}}$ \\
\hline UK & 0.099 & $(0.931)$ & -0.243 & $(0.867)$ & -0.388 & $(0.640)$ & 5.370 & $(0.021)^{\mathrm{b}}$ \\
\hline
\end{tabular}


Table 7. (continued)

\begin{tabular}{|c|c|c|c|c|c|c|c|c|}
\hline \multirow[b]{2}{*}{ Market } & \multicolumn{4}{|c|}{ Relative HSP/LSP (I) } & \multicolumn{4}{|c|}{ Moving HSP/LSP (II) } \\
\hline & $\beta_{1}$ & prob. & $\boldsymbol{\beta}_{2}$ & prob. & $\beta_{1}$ & prob. & $\boldsymbol{\beta}_{2}$ & prob. \\
\hline \multicolumn{9}{|c|}{ Panel D: EGARCH } \\
\hline Austria & 2.028 & $(0.364)$ & -5.129 & $(0.038)^{\mathrm{b}}$ & 2.364 & $(0.335)$ & -5.416 & $(0.042)^{\mathrm{b}}$ \\
\hline Belgium & 2.788 & $(0.227)$ & -5.460 & $(0.033)^{\mathrm{b}}$ & 1.187 & $(0.530)$ & -4.701 & $(0.035)^{b}$ \\
\hline Denmark & 0.446 & $(0.882)$ & -3.597 & $(0.272)$ & 2.557 & $(0.483)$ & -5.864 & $(0.128)$ \\
\hline France & 1.587 & $(0.501)$ & -2.996 & $(0.257)$ & 1.932 & $(0.396)$ & -3.346 & $(0.195)$ \\
\hline Germany & 3.866 & $(0.116)$ & -4.774 & $(0.084)^{\mathrm{c}}$ & 1.286 & $(0.508)$ & -2.691 & $(0.273)$ \\
\hline Ireland & -0.268 & $(0.867)$ & -3.662 & $(0.059)^{\mathrm{c}}$ & -3.535 & $(0.001)^{\mathrm{a}}$ & 2.839 & $(0.219)$ \\
\hline Italy & -0.819 & $(0.537)$ & 4.596 & $(0.043)^{\mathrm{b}}$ & 2.864 & $(0.244)$ & -1.797 & $(0.514)$ \\
\hline Luxembourg & -0.507 & $(0.923)$ & -4.547 & $(0.446)$ & -2.359 & $(0.618)$ & 1.141 & $(0.842)$ \\
\hline Netherlands & 2.272 & $(0.218)$ & -3.475 & $(0.085)^{c}$ & -0.126 & $(0.926)$ & -1.157 & $(0.488)$ \\
\hline Norway & 1.395 & $(0.514)$ & -2.166 & $(0.345)$ & 1.836 & $(0.385)$ & -2.707 & $(0.237)$ \\
\hline Spain & 2.263 & $(0.320)$ & -1.293 & $(0.626)$ & -0.233 & $(0.878)$ & 3.770 & $(0.114)$ \\
\hline Sweden & 3.905 & $(0.035)^{\mathrm{b}}$ & -5.803 & $(0.006)^{\mathrm{a}}$ & 0.280 & $(0.891)$ & -1.226 & $(0.595)$ \\
\hline Switzerland & 3.354 & $(0.078)^{\mathrm{c}}$ & -5.401 & $(0.010)^{\mathrm{b}}$ & 2.415 & $(0.144)$ & -4.846 & $(0.010)^{b}$ \\
\hline UK & 0.450 & $(0.777)$ & -0.568 & $(0.772)$ & -0.512 & $(0.632)$ & 5.630 & $(0.027)^{b}$ \\
\hline
\end{tabular}

This table reports panel results from 14 individual European stock markets by assessing the relationship between excess returns and conditional variance. Results are conditional on HSPs and LSPs according to the relative reference approach (RRA, Column I) and the moving-average reference approach (MRA, Column II). For the RRA, we first calculate the average of the $\mathrm{CCI}$ in each stock market over all periods and regard it as the relative reference value, or in other words, the normal sentiment state. We then compare the average CCI in calendar year $T$ with the wholeperiod average CCI: If the former is higher (lower), the next calendar year $(T+1)$ is identified as the HSP (LSP). For MRA, we first calculate the past three-year average of the CCI in each stock market from year $(T-3)$ to year $(T$ $-1)$. We replicate the above comparison: If the average CCI in calendar year $T$ is higher (lower), the next calendar year $(T+1)$ is categorized as the HSP(LSP). The regression specification is,

$$
R_{t+1}=\alpha_{1}+\alpha_{2} D_{t}+\beta_{1} \operatorname{Var}_{t}\left(R_{t+1}\right)+\beta_{2} D_{t} \operatorname{Var}_{t}\left(R_{t+1}\right)+\xi_{t+1} \text {, }
$$

where $D_{t}$ is the dummy variable for HSPs - that is $D_{t}=1$ over HSPs while $D_{t}=0$ over LSPs. Panel A, B, C, and D presents results from the RW, GARCH, GJR-GARCH, and EGARCH models, accordingly.

${ }^{\mathrm{a}}{ }^{\mathrm{b}}$, and ${ }^{\mathrm{c}}$ represent statistical significance at the $1 \%, 5 \%$, and $10 \%$ level, respectively. 
The results from the RSS largely mirror the theoretical analysis. Over LSPs, there is a risk-return tradeoff, from 0.722 (RW) to 1.298 (EGARCH). For instance, a 1\% upward (downward) revision in conditional volatility causes a $1.135 \%$ increase (decrease) in stock returns over LSPs (GJRGARCH). However, over HSPs, the risk-return tradeoff disappear and instead, there is a negative mean-variance relationship, from $-1.633(1.298-2.931$, EGARCH) to $-1.311(1.135-2.446$, GJR-GARCH). This pattern holds in the balanced dataset as well, with larger magnitude form $0.920(\mathrm{RW})$ to 1.337 (GJR-GARCH) over LSPs, and from -2.548 (1.316 - 3.865, EGARCH) to $1.833(1.337-3.220$, GJR-GARCH) over HSPs.

This evidence implies that whether investors participate in stock trading is not exclusively subject to their nominal optimism/pessimism given by the CCI surveys (i.e., above or below NVs), but more importantly, their real optimism/pessimism compared with their normal sentiment state. Simply, when investors are relatively optimistic (pessimistic), they are likely (not) to trade in stock market. Their participation over HSPs distorts the presented risk-return tradeoff over LSPs. The similar case appears in individual market results, except that Italy consistently gives significantly positive estimation of $\beta_{2}$.

Results from the MRA also confirm that individual investors' participation tends to distort the risk-return tradeoff over HSPs. However, different from the RRA, we do not find any significant relationship over LSPs. Note that to some extent, the MRA is a special case of the RRA because the RRA is the moving average based on the whole period and with the window length increases, the MRA conceptually approaches to the RRA. Observing the relatively weaker results from the MRA, we conjecture that investors not only care about their normal sentiment level, but also allocate more weights on the longer term. In an un-tabulated result, we set the MRA window length to be one year and the results become weaker and more mixed, which confirms our conjecture. For the individual market MRA results, the UK is the only market presenting significantly positive mean-variance relationship across all four models. 
Our results provide some simple trading ideas for investors. Albeit the adopted three segregation approaches do not provide exactly consistent results, generally, HSPs are likely to see the negative mean-variance relationship. Exposure to higher risk over HSPs does not guarantee higher returns as standard financial theories speak, but instead, it normally brings about lower returns. Besides, according to the RRA, investors are rewarded by bearing more risk over LSPs given the risk-return tradeoff.

\section{Conclusions}

We examine the mean-variance relationship in 14 European markets, conditional on the levels of investor sentiment. Evidence reveals that individual investors' high participation in stock trading over the high-sentiment periods tends to distort the risk-return tradeoff. By individual market investigation, we find that the impact of investor sentiment on the mean-variance relationship is not supported in all markets, but market-specific. More importantly, investors' decisions on stock trading are dependent not only on their nominal sentiment levels disclosed by sentiment surveys, but also on their sentiment levels relative to the normal sentiment state.

Our paper extends evidence in Yu and Yuan (2011) by offering findings out of the US stock market. However, we acknowledge the following three limitations and potential research avenues. First, while we extend the extant evidence on the impact of investor sentiment on 14 European markets, more work may usefully focus on emerging markets due to their diversified investment opportunities, which seems constructive to investors as well. Second, we confirm the impact of investor sentiment on the mean-variance relationship to be market-specific, implying that in addition to investor sentiment, other factors potentially involving culture and market institutions may be also key to the determination (Schmeling, 2009). We leave it to future research to explore this further. Third, to have the better insight into investors' behaviors over HSPs and LSPs, direct 
evidence from the brokerage-level data demonstrating changes in retail investors' positions may be of helpfulness. 


\section{Appendix}

Four types of proxies are proposed to measure investor sentiment in literature and they are direct, indirect, composite, and innovative.

Direct proxies comes from surveys or questionnaires directly asking consumers or investors about their propensity to consume or invest in the future. In studies investigating the US stock market, the data from American Association of Individual Investor (AAII) is widely adopted (Brown, 1999; Fisher and Statman, 2000; Wang et al., 2006). The AAII reflects investor sentiment by computing the proportion of individual investors classifying themselves as bearish, bullish, or neutral about stock markets in subsequent six months. Much research also adopts the consumer confidence index in that when consumers are optimistic (pessimistic) about the economy, they would also be more (less) likely to trade in stock markets and vice versa (Qiu and Welch, 2006; Schmeling, 2009). Indirect proxies are sourced from financial markets, and more importantly, solid theoretical underpinnings about the relationship between the proxy and investor sentiment should be explicitly established. For example, the closed-end fund discount (CEFD) is one contrarian indirect proxy given that it is proved negatively associated with investor sentiment (Lee et al., 1991; Swaminathan, 1996; Neal and Wheatley, 1998) — that is high (low) investor sentiment is reflected by low (high) CEFDs. Other widely-used indirect proxies include option implied volatility (Baker and Wurgler, 2007; Smales, 2017), initial public offerings (IPO) first day returns and volume (Baker and Wurgler, 2006), and mutual fund flows (Frazzini and Lamont, 2008). Composite proxies build on two or more direct and/or indirect proxies. One important composite proxy is the BW index from Baker and Wurgler (2006) that encompasses six single proxies including the CEFD, the dividend premium, the equity share in new issues, the New York Stock Exchange share turnover, the number of IPOs, and average first-day returns on IPOs by the principal component analysis approach. The BW index is widely adopted in prior literature (Chung et al., 2012; Antoniou et al., 2016) and under improvement (Huang et al., 2015). Based on mass 
media and the Internet, a handful of innovative proxies are proposed in more recent research (Da et al., 2011, 2015; Karampatsas et al., 2017). Tetlock (2007), for instance, compiles an index for media pessimism as the investor sentiment proxy by collecting the content from the Wall Street Journal column. Despite various proposed fine proxies, the choice should depend on research questions per se. 
Acknowledgements

We thank the editor, John Goodell and two anonymous referees for helpful comments. 


\section{References}

Ang, A., Bekaert, G., 2007. Stock return predictability: Is it there? Rev. Financ. Stud. 20 (3), 651-707. http://dx.doi.org/10.1093/rfs/hhl021.

Ang, A., Hodrick, R.J., Xing, Y., Zhang, X., 2009. High idiosyncratic volatility and low returns: International and further U.S. evidence. J. Financ. Econ. 91 (1), 1-23. http://dx.doi.org/10.1016/j.jfineco.2007.12.005.

Antoniou, C., Doukas, J.A., Subrahmanyam, A., 2016. Investor sentiment, beta, and the cost of equity capital. Manag. Sci. 62 (2), 347-367. http://dx.doi.org/10.1287/mnsc.2014.2101.

Baillie, R.T., DeGennaro, R.P., 1990. Stock returns and volatility. J. Financ. Quant. Anal. 25 (2), 203-214. http://dx.doi.org/10.2307/2330824.

Baker, M., Bradley, B., Wurgler, J., 2011. Benchmarks as limits to arbitrage: Understanding the low-volatility anomaly. Financ. Anal. J. 67 (1), 40-54. https://doi.org/10.2469/faj.v67.n1.4.

Baker, M., Wurgler, J., 2006. Investor sentiment and the cross-section of stock returns. J. Finance 61 (4), 1645-1680. http://dx.doi.org/10.1111/j.1540-6261.2006.00885.x.

Baker, M., Wurgler, J., 2007. Investor sentiment in the stock market. J. Econ. Perspect. 21 (2), 129-151. http://dx.doi.org/10.1257/jep.21.2.129.

Barber, B.M., Odean, T., 2008. All that glitters: The effect of attention and news on the buying behavior of individual and institutional investors. Rev. Financ. Stud. 21 (2), 785-818. http://dx.doi.org/10.1093/rfs/hhm079.

Bollerslev, T., 1986. Generalized autoregressive conditional heteroskedasticity. J. Econometrics 31 (3), 307-327. http://dx.doi.org/10.1016/0304-4076(86)90063-1.

Booth, G.G., Fung, H.G., Leung, W.K., 2016. A risk-return explanation of the momentumreversal "anomaly". J. Empir. Finance 35, 68-77. https://doi.org/10.1016/j.jempfin.2015.10.007.

Brandt, M., Kang, Q., 2004. On the relationship between the conditional mean and volatility of stock returns: A latent VAR approach. J. Financ. Econ. 72 (2), 217-257. http://dx.doi.org/10.1016/j.jfineco.2002.06.001.

Brandt, M., Wang, L., 2010. Measuring the time-varying risk-return relation from the crosssection of equity returns. Working paper, Duke University.

Brown, G.W., 1999. Volatility, sentiment, and noise traders. Financ. Anal. J. 55 (2), 82-90. http://dx.doi.org/10.2469/faj.v55.n2.2263.

Brown, G.W., Cliff, M.T., 2005. Investor sentiment and asset valuation. J. Bus. 78 (2), 405-440. http://dx.doi.org/10.1086/427633. 
Campbell, J.Y., 1987. Stock returns and the term structure. J. Financ. Econ. 18 (2), 373-399. http://dx.doi.org/10.1016/0304-405X(87)90045-6.

Campbell, J.Y., Hentschel, L., 1992. No news is good news: An asymmetric model of changing volatility in stock returns. J. Financ. Econ. 31 (3), 281-318. http://dx.doi.org/10.1016/0304-405X(92)90037-X.

Chung, S., Hung, C., Yeh, C., 2012. When does investor sentiment predict stock returns? J. Empir. Finance 19 (2), 217-240. http://dx.doi.org/10.1016/j.jempfin.2012.01.002.

Corsi, F., 2009. A simple approximate long-memory model of realized volatility. J. Financ. Econometrics 7 (2), 174-196. http://dx.doi.org/10.1093/jjfinec/nbp001.

Da, Z., Engelberg, J., Gao, P., 2011. In search of attention. J. Finance 66 (5), 1461-1499. http://dx.doi.org/10.1111/j.1540-6261.2011.01679.x.

Da, Z., Engelberg, J., Gao, P., 2015. The sum of all FEARS investor sentiment and asset prices. Rev. Financ. Stud. 28 (1), 1-32. http://dx.doi.org/10.1093/rfs/hhu072.

De Long, J.B., Shleifer, A., Summers, L.H., Waldmann, R.J., 1990. Noise trader risk in financial markets. J. Polit. Econ. 98 (4), 703-738. http://dx.doi.org/10.1086/261703.

Engle, R.F., 1982. Autoregressive conditional heteroscedasticity with estimates of the variance of United Kingdom Inflation. Econometrica 50 (4), 987-1007. http://dx.doi.org/10.2307/1912773.

Engle, R.F., 2001. GARCH 101: The use of ARCH/GARCH models in applied econometrics. J. Econ. Perspect. 15 (4), 157-168. http://dx.doi.org/10.1257/jep.15.4.157.

Fama, E.F., 1965. The behavior of stock-market prices. J. Bus. 38 (1), 34-105. http://dx.doi.org/10.1086/294743.

Fiore, C., Saha, A., 2015. A Tale of two anomalies: Higher returns of low-risk stocks and return seasonality. Financ. Rev. 50 (2), 257-273. http://dx.doi.org/10.1111/fire.12066.

Fisher, K.L., Statman, M., 2000. Investor sentiment and stock returns. Financ. Anal. J. 56 (2), 16-23. http://dx.doi.org/10.2469/faj.v56.n2.2340.

Frazzini, A., Lamont, O.A., 2008. Dumb money: Mutual fund flows and the cross-section of stock returns. J. Financ. Econ. 88 (2), 299-322. http://dx.doi.org/10.1016/j.jfineco.2007.07.001.

French, K.R., Schwert, W., Stambaugh, R.F., 1987. Expected stock returns and volatility. J. Financ. Econ. 19 (1), 3-29. http://dx.doi.org/10.1016/0304-405X(87)90026-2.

Ghysels, E., Santa-Clara, P., Valkanov, R., 2005. There is a risk-return trade-off after all. J. Financ. Econ. 76 (3), 509-548. http://dx.doi.org/10.1016/j.jfineco.2004.03.008. 
Glosten, L.R., Jagannathan, R., Runkle, D.E., 1993. On the relation between the expected value and the volatility of the nominal excess return on stocks. J. Finance 48 (5), 1779-1801. http://dx.doi.org/10.1111/j.1540-6261.1993.tb05128.x.

Griffin, J.M., Ji, X., Martin, J.S., 2003. Momentum investing and business cycle risk: Evidence from pole to pole. J. Finance 58 (6), 2515-2547. http://dx.doi.org/10.1046/j.15406261.2003.00614.x.

Guo, H., Whitelaw, R.F., 2006. Uncovering the risk-return relation in the stock market. J. Finance 61 (3), 1433-1463. http://dx.doi.org/10.1111/j.1540-6261.2006.00877.x.

Harvey, C.R., 2001. The specification of conditional expectations. J. Empir. Finance 8 (5), $573-$ 638. http://dx.doi.org/10.1016/S0927-5398(01)00036-6.

Huang, D., Jiang, F., Tu, J., Zhou, G., 2015. Investor sentiment aligned: A powerful predictor of stock returns. Rev. Financ. Stud. 28 (3), 791-837. http://dx.doi.org/10.1093/rfs/hhu080.

Karampatsas, N., Malekpour, S., Mason, A., 2017. Beyond market mood: Stock sentiment and the response to corporate earnings announcements. Working paper, University of Surrey.

Karlsson, N., Loewenstein, G., Seppi, D., 2009. The ostrich effect: Selective attention to information. J. Risk Uncertain. 38 (2), 95-115. http://dx.doi.org/10.1007/s11166-0099060-6.

Lee, C.M.C., Shleifer, A., Thaler, R.H., 1991. Investor sentiment and the closed-end fund puzzle. J. Finance 46 (1), 75-109. http://dx.doi.org/10.1111/j.1540-6261.1991.tb03746.x.

Lemmon, M., Portniaguina, E., 2006. Consumer confidence and asset prices: Some empirical evidence. Rev. Financ. Stud. 19 (4), 1499-1529. http://dx.doi.org/10.1093/rfs/hhj038.

Lettau, M., Ludvigson, S.C., 2010. Measuring and modeling variation in the risk-return trade-off, in: Ait-Sahalia, Y., Hansen, L.P. (Eds.), Handbook of Financial Econometrics: Tools and Techniques. North-Holland, Amsterdam, pp. 617-690.

Ludvigson, S.C., Ng, S., 2007. The empirical risk-return relation: A factor analysis approach. J. Financ. Econ. 83 (1), 171-222. http://dx.doi.org/10.1016/j.jfineco.2005.12.002.

Lundblad, C., 2007. The risk return tradeoff in the long run: 1836-2003. J. Financ. Econ. 85 (1), 123-150. http://dx.doi.org/10.1016/j.jfineco.2006.06.003.

Lux, T., 1998. The socio-economic dynamics of speculative markets: Interacting agents, chaos, and the fat tails of return distributions. J. Econ. Behav. Organ. 33 (2), 143-165. http://dx.doi.org/10.1016/S0167-2681(97)00088-7.

Merton, R.C., 1973. An intertemporal capital asset pricing model. Econometrica 41 (5), 867877. http://dx.doi.org/10.2307/1913811. 
Merton, R.C., 1980. On estimating the expected return on the market: An exploratory investigation.”J. Financ. Econ. 8 (4): 323-361. http://dx.doi.org/10.1016/0304405X(80)90007-0.

Neal, R., Wheatley, S.M., 1998. Do measures of investor sentiment predict returns? J. Financ. Quant. Anal. 33 (4), 523-547. http://dx.doi.org/10.2307/2331130.

Nelson, D.B., 1991. Conditional heteroskedasticity in asset returns: a new approach. Econometrica 59 (2), 347-370. http://dx.doi.org/10.2307/2938260.

Qiu, L., Welch, I., 2006. Investor sentiment measures. Working paper, National Bureau of Economic.

Pástor, L., Sinha, M., Swaminathan, B., 2008. Estimating the intertemporal risk-return tradeoff using the implied cost of capital. J. Finance 63 (6), 2859-2897. http://dx.doi.org/10.1111/j.1540-6261.2008.01415.x.

Rossi, A.G., Timmermann, A., 2015. Modeling covariance risk in Merton's ICAPM. Rev. Financ. Stud. 28 (5), 1428-1461. http://dx.doi.org/10.1093/rfs/hhv015.

Schmeling, M., 2009. Investor sentiment and stock returns: Some international evidence. J. Empir. Finance 16 (3), 394-408. http://dx.doi.org/10.1016/j.jempfin.2009.01.002.

Scruggs, J.T., 1998. Resolving the puzzling intertemporal relation between the market risk premium and conditional market variance: A two-factor approach. J. Finance 52 (3), 575-603. http://dx.doi.org/10.1111/0022-1082.235793.

Shleifer, A., Vishny, R.W., 1997. The limits of arbitrage. J. Finance 52 (1), 35-55. http://dx.doi.org/ j.1540-6261.1997.tb03807.x.

Smales, L.A., 2017. The importance of fear: investor sentiment and stock market returns. Appl. Econ. 49 (34), 3395-3421. https://doi.org/10.1080/00036846.2016.1259754.

Sun, L., Meng, L., Najand, M., 2017. The role of U.S. market on international risk-return tradeoff relations. Financ. Rev. 52 (3), 499-526. http://dx.doi.org/10.1111/fire.12139.

Swaminathan, B., 1996. Time-varying expected small firm returns and closed-end fund discount. Rev. Financ. Stud. 9 (3), 845-887. http://dx.doi.org/10.1093/rfs/9.3.845.

Tetlock, P.C., 2007. Giving content to investor sentiment: The role of media in the stock market. J. Finance 62 (3), 1139-1168. http://dx.doi.org/10.1111/j.1540-6261.2007.01232.x.

Turner, C.M., Startz, R., Nelson, C.R., 1989. A Markov model of heteroskedasticity, risk, and learning in the stock market. J. Financ. Econ. 25 (1), 3-22. http://dx.doi.org/10.1016/0304-405X(89)90094-9.

Wang, H., Yan, J., Yu., J., 2017. Reference-dependent preferences and the risk-return trade-off. J. Financ. Econ. 123 (2), 395-414. https://doi.org/10.1016/j.jfineco.2016.09.010. 
Wang, Y.H., Keswani, A., Taylor, S.J., 2006. The relationships between sentiment, returns and volatility. Int. J. Forecast. 22 (1), 109-123. http://dx.doi.org/10.1016/j.ijforecast.2005.04.019.

Whitelaw, R.F., 1994. Time variations and covariations in the expectation and volatility of stock market returns. J. Finance 49 (2), 515-541. http://dx.doi.org/10.1111/j.15406261.1994.tb05150.x.

Yu, J., Yuan, Y., 2011. Investor sentiment and the mean-variance relation. J. Financ. Econ. 100 (2), 367-381. http://dx.doi.org/10.1016/j.jfineco.2010.10.011. 